\title{
EL DISEÑO URBANO DE LA REGIO IV DE COMPLUTUM (ALCALÁ DE HENARES). ESTUDIOS A PARTIR DE LA PROSPECCIÓN GEOFÍSICA
}

\author{
URBAN DESIGN IN THE REGIO IV OF COMPLUTUM (ALCALÁ DE HENARES). STUDIES BASED ON \\ GEOPHYSICAL PROSPECTION
}

\author{
CÈSAR CARRERAS \\ Universitat Autònoma de Barcelona \\ cesar.carreras@uab.cat \\ http://orcid.org/0000-0003-4300-9470 \\ PAU OLMOS \\ Institut Català d'Arqueologia Clàssica \\ polmos@icac.cat \\ http://orcid.org/0000-0002-9755-1110
}

\author{
SEBASTIÁN RASCÓN MARQUÉS \\ Servicio Municipal de Arqueología \\ Ayuntamiento de Alcalá de Henares \\ Universidad Autónoma de Madrid \\ sebasrascon@gmail.com \\ http://orcid.org/0000-0002-7835-3952
}

\author{
ANA LUCÍA SÁNCHEZ MONTES \\ Universidad Autónoma de Madrid \\ aluciasmontes@gmail.com \\ http://orcid.org/0000-0002-6274-6735 \\ PAU DE SOTO \\ Programa Marie Curie \\ Universidade Nova de Lisboa \\ paudsoto@gmail.com \\ http://orcid.org/0000-0002-7068-786X
}

Recepción: 14-11-2016

Aceptación: 21-02-2017

\section{Resumen}

Se presenta la investigación realizada sobre la traza urbana de la regio IV de la ciudad romana de Complutum. Se realiza una prospección eléctrica acompañada por el estudio de algunos restos excavados recientemente y de la documentación procedente de excavaciones del siglo XIX. Como resultado, ha sido posible generar una nueva propuesta de diseño urbano para la regio IV, basada en una trama ortogonal de insulae de 30x30 m, e identificar diversas estructuras entre las que destaca un edificio singular que con todas las precauciones debidas podría tratarse de un santuario urbano de importantes dimensiones.

Palabras clave. Prospección geofísica; Urbanismo romano; Complutum; Templo romano

\begin{abstract}
The paper shows the research on the urban pattern of the regio IV of the Roman city of Complutum: a geophysical survey accompanied by the study of some archaeological remains recently excavated, and the documentation from some 19th century excavations. Therefore, it has been possible to generate a new urban design proposal for the regio IV, and to identify different archaeological buildings, specially one that might have been an urban sanctuary of important dimensions.
\end{abstract}

Key words. Geophysical survey; Roman urbanism; Complutum; Roman temple. 


\section{COMPLUTUM: URBANISMO Y PROBLEMAS DE IDENTIFICACIÓN DEL DISEÑO URBANO EN LA REGIO IV}

\section{IDENTIFICACIÓN DEL URBANISMO DE COMPLUTUM}

Los últimos años de investigaciones en la ciudad romana de Complutum, actual Alcalá de Henares, han permitido disponer de hipótesis bien fundadas sobre el urbanismo complutense. Históricamente y ya desde el siglo XVI habían existido autores que venían esbozando algunas líneas maestras sobre la ubicación de la ciudad, a partir sobre todo de la obra de Ambrosio de Morales, hacia 1577 (Abascal, 2012: 49 y 51). Esta inquietud se ha mantenido a lo largo del tiempo, tal y como varios autores modernos han reflejado (Rascón Marqués, 2004, I: 23 y ss.; Vallejo, 2005) y como evidencia a modo de ejemplo, el trabajo de Calleja, donde ya se da cuenta de la existencia de dos emplazamientos, uno más antiguo en el cerro del Viso (que él, acorde con las teorías circulantes en ese momento sobre la historia antigua, llama Iplacea y asocia con los griegos), otro más moderno en la vega del Henares (1898: 187, n.1), y sobre todo de las dimensiones aproximadas de esta última ciudad de la vega, a partir por cierto de criterios arqueológicos inspirados por una metodología no muy alejada de la actual, aunque todavía sin recursos técnicos (1898: 40 y ss.). Pero todavía se trataba tan solo de presentar un esquema básico, que respondía a dos ideas generales: primero, la existencia del ya referido doble asentamiento, uno generalmente reconocido como más antiguo, en el cerro de San Juan del Viso; y otro, tradicionalmente entendido como más moderno, en el que se centran la mayoría de los trabajos, y de dimensiones muy notables, en la vega del Henares, al pie del cerro; y estando ambos lugares separados por este río (Fig. 1); la segunda idea era la identificación en la vega de una serie de hitos arqueológicos, inscripciones, edificios romanos más o menos evidentes, y una cierta topografía antigua, en general centrada en torno a los restos más reconocibles, principalmente la fuente del Juncal, el Paredón del Milagro y el camino del Juncal.

Este interés y conocimiento de Complutum, que fue relativamente abundante (Vallejo, 2005), no sólo dirigido a su urbanismo, sino también a otros varios aspectos, se esfuma a partir de la Guerra Civil española, y el yacimiento cae prácticamente en el olvido. Será en 1970, y tras décadas de desinterés casi absoluto, cuando se produzca su traumático redescubrimiento por parte de la arqueología moderna, al hilo del desordenado y agresivo crecimiento de la moderna Alcalá de Henares; es entonces cuando Fernández-Galiano propone un primer borrador del diseño urbano de la ciudad de la vega: se sigue tratando de líneas muy elementales, circunscritas a un perímetro urbano, una serie de áreas funerarias y un diseño interior donde se perciben un cardo y un decumano (Fernández-Galiano, 1984: 393 y ss.).

La continuada investigación arqueológica desarrollada en el yacimiento a lo largo de las décadas de 1990 y 2000, que además de la excavación arqueológica incluía varias líneas metodológicas de actuación, entre ellas la arqueología preventiva y la prospección geofísica, propició que Rascón Marqués propusiese una primera hipótesis altamente contrastada sobre el urbanismo y el diseño urbano complutenses, sobre todo el referido al núcleo principal, el de la vega del Henares (Rascón Marqués, 2004). Hipótesis que en sus líneas generales es la que sigue válida hoy en día, aunque determinadas áreas de la ciudad aún no tenían datos suficientes para interpretar su trama urbana, especialmente las llamadas regiones I y IV. A lo largo de

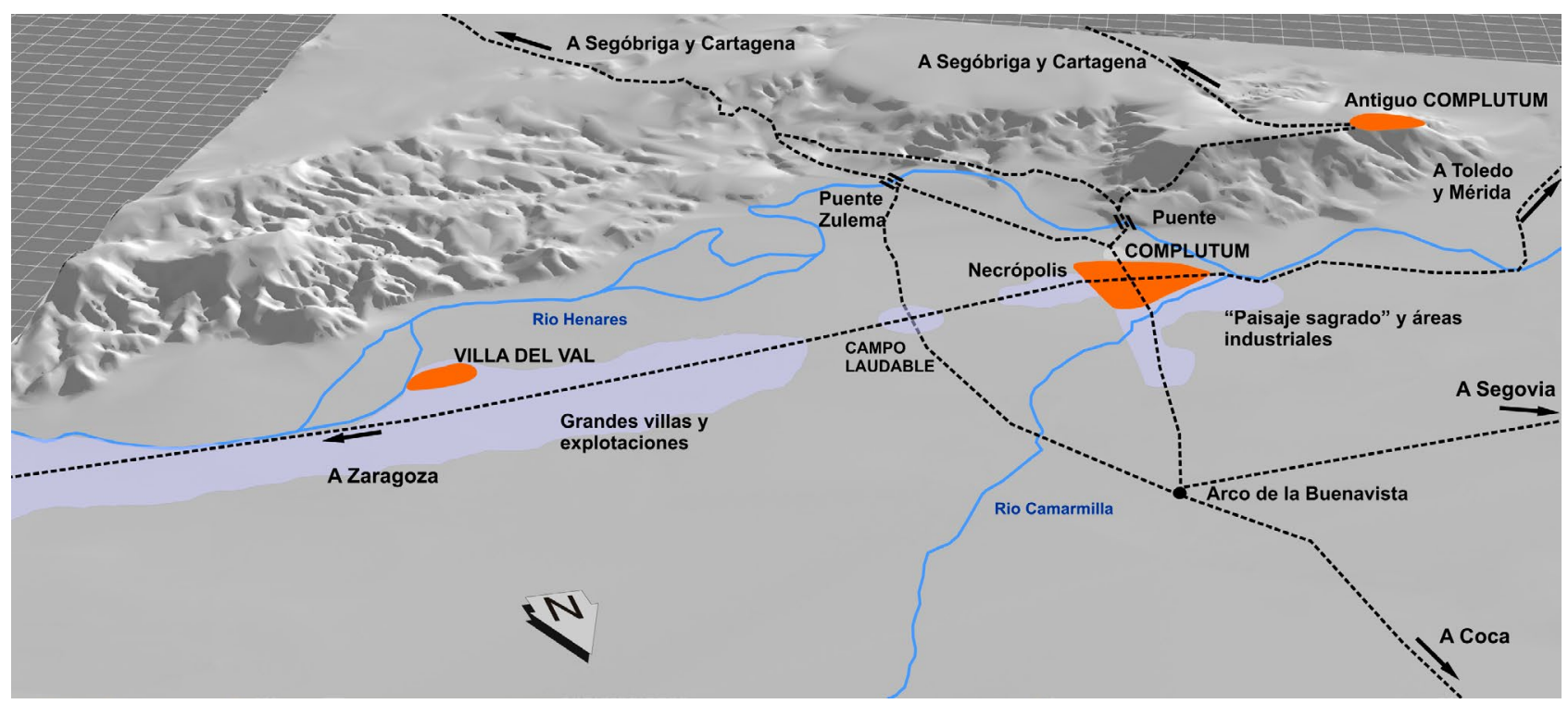

Figura 1: Modelo digital mostrando la posición de la primera fundación de Complutum en el Viso y la segunda y definitiva en la vega del Henares. 
los diez años siguientes, también gracias al progreso de la investigación arqueológica en esta ciudad romana, aquella hipótesis fue depurada progresivamente por Sánchez Montes y por el mismo Rascón Marqués, tanto en lo referido al diseño urbano como a su desarrollo general en relación con fases anteriores y posteriores de la historia de Complutum-Alcalá de Henares (Rascón Marqués y Sánchez Montes, 2014a; 2014b; 2015). Así como a aspectos muy particulares del diseño urbano, como es la red de saneamiento, que han sido tratados en detalle (Rascón Marqués y Sánchez Montes, 2013). Paralelamente, ha habido acercamientos para reconocer un diseño urbano en el cerro de San Juan del Viso. También en este caso los primeros conocimientos se deben a excavaciones desarrolladas por Fernández-Galiano (1984: 23 y ss.), aunque más recientemente Azcárraga y Ruiz Taboada (2013) han sido capaces de determinar a través de la teledetección el esquema básico de un diseño urbano y unas determinadas edificaciones.

\section{Diseño urbano de Complutum}

Todo parece indicar que el primer ensayo urbano formal documentable para la configuración de la ciudad romana de Complutum, se situó en la plataforma sobre el cerro de San Juan del Viso, dominando el valle del río Henares. A pesar de que el yacimiento es todavía muy poco conocido, se distingue con claridad la existencia de un diseño urbano: hay edificios públicos, como unas termas que incluso han sido objeto de excavación arqueológica (Fernández-Galiano, 1984: 59 y ss.). Se detecta por medio de la fotografía aérea un muy probable templo, incluso aparentemente un teatro y una trama ortogonal bastante evidente y ceñida a un formato de aproximadamente $30 \times 30 \mathrm{~m}$, todo ello con una superficie cercana a las 30 ha (Azcárraga y Ruiz Taboada, 2013: 102 y ss.). Más difícil es el establecimiento preciso de una cronología para este asentamiento, ya que se carece por completo de datos estratigráficos. Los tres investigadores citados (Fernández-Galiano, 1984: 75 y ss.; Azcárraga y Ruiz Taboada, 2013: 109 y ss.), pero también Rascón y Sánchez Montes (2010: 340) asumen que este diseño podría fecharse a finales de la época republicana, y consideran que esta ciudad del cerro se «desmontaría» en el siglo I d.C. para construir una nueva fundación en la vega del Henares. Esta es la hipótesis tradicional, sobre la que sin embargo cabe mantener cierta cautela, dada la escasez de los criterios que pueden esgrimirse para defender estas cronologías. Rascón y Sánchez Montes han apuntado también, más recientemente, la posibilidad de una convivencia de ambos núcleos, aunque el del cerro, a partir de cierta fecha, podría quedar como una especie de acrópolis en relación suburbana con respecto al de la vega (2014a: 311).

El núcleo principal del Complutum romano no se va a situar en altura, sino más bien en la fértil vega del Henares, construido con un primer impulso en época de Augusto, pero ejecutado con un gran esfuerzo económico y como ciudad de nueva planta a mediados del siglo I d.C., a finales de la época neroniana o en época de Claudio. El estudio del urbanismo de esta ciudad de la vega ha contado con una diversidad de métodos, incluyendo las cartas arqueológicas; los datos sobre parcelaciones antiguas del suelo, toponimia y topografía histórica; la revisión de documentos procedentes de las antiguas excavaciones de Complutum; varios proyectos de teledetección en primavera de 2000, primavera de 2001 (Kermorvant y González, 2000; 2001), 2006 (López y Martínez, 2006) y 2009 (Cóndor Georadar, 2009); la relectura de los espacios arqueológicos excavados en la década de 1970; y por último la arqueología reciente de la ciudad de Alcalá, tanto el seguimiento técnico de la zona de Reyes Católicos, moderna barriada construida entre 1970 y 1974 sobre buena parte de Complutum romano, como los programas sistemáticos de intervención que el Servicio de Arqueología Municipal ha desarrollado en el yacimiento, y que sobre todo ha afectado a la superficie no construida del mismo con fines de investigación, conservación y valorización.

Gracias a ello se dispone de numerosos datos sobre este diseño urbano, que ha sido expuesto en detalle por Rascón Marqués y Sánchez Montes (2014b; 2015), y que se ciñe a un formato característico del urbanismo romano, una trama ortogonal de algo más de 50 ha sobre una superficie plana en la vega del río Henares, y a la que deben añadirse varios suburbios. Sus límites son relativamente claros, ceñidos por la parte occidental a la confluencia de los ríos Henares y Camarmilla. Diversos datos han venido avalando una estructura de este núcleo principal en manzanas cuadradas que se pueden repartir en seis regiones; regiones que en gran parte responden a parámetros reales de la topografía antigua, muy especialmente los números I, II y IV (Rascón Marqués, 2004, III: 83 y ss.), y que sin duda son muy útiles a nivel descriptivo en la investigación. Así, el decumano máximo de la ciudad, fosilizado históricamente en la calle Camino del Juncal, separa al Sur a las regiones I, II y III, y al Norte a las IV, V y VI (en ambos casos, numerados de Oeste a Este).

La estructura urbana complutense general se articula por medio de manzanas de 30x30 m. Si a estas les añadimos los pórticos, resulta una estructura racional de $36 \times 36 \mathrm{~m}$ por manzana, que nos remite a cuadrados de $1 \times 1$ actus (Fig. 2), con la salvedad de las regiones I y II, muy poco conocidas, y para las que hasta ahora y en función de los datos de las prospecciones de 2000 y 2001, se había propuesto un formato rectangular cercano a 1x1,5 actus. El diseño general de esta trama se percibe también en los edificios públicos: el gran complejo administrativo anejo al foro, que desde finales del siglo III ocupa una primitiva basílica, unas termas y un cuadripórtico, se ajusta también a esta 


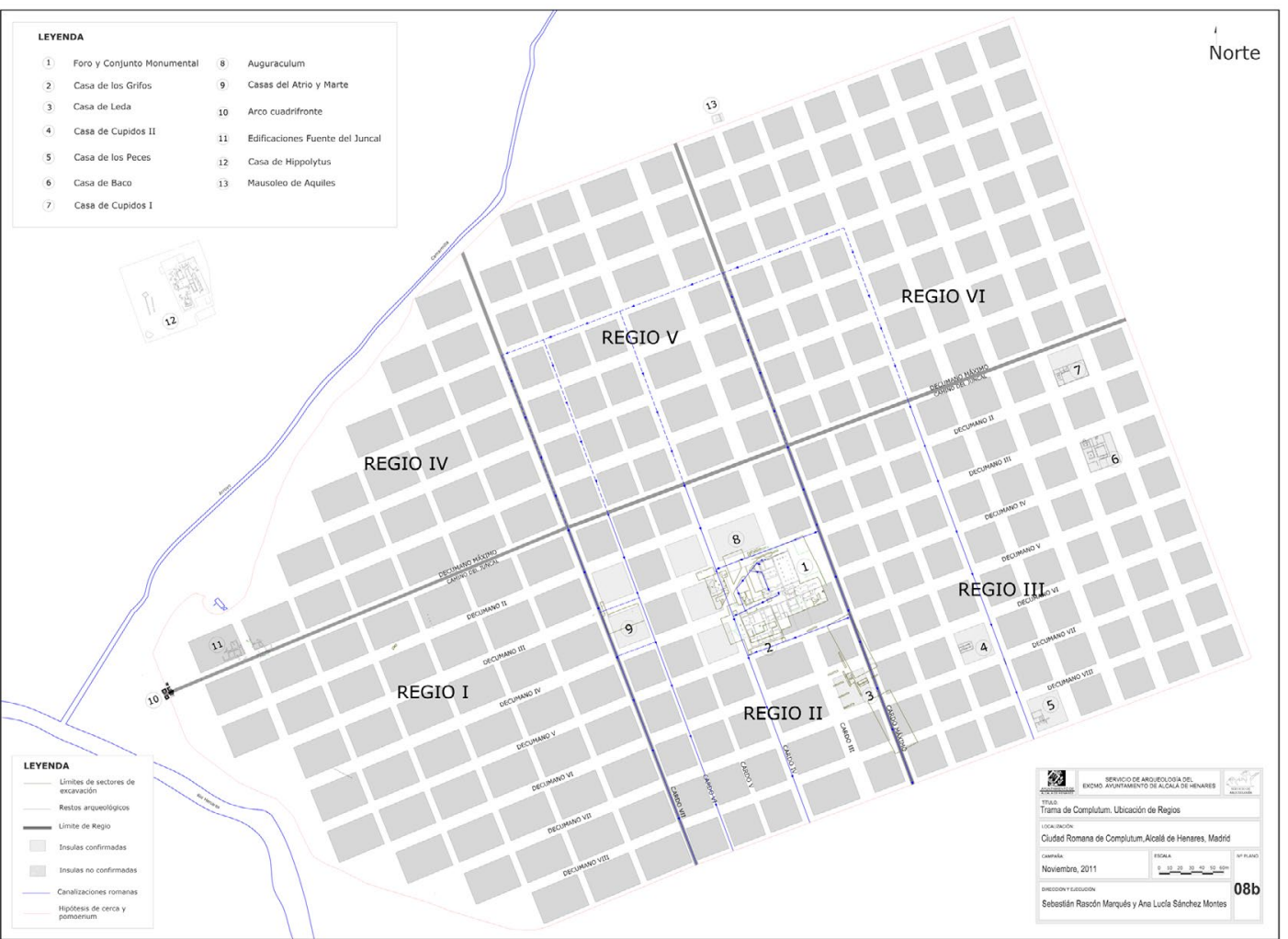

Figura 2: Hipótesis con la estructura urbana de Complutum, antes de la prospección geofísica.

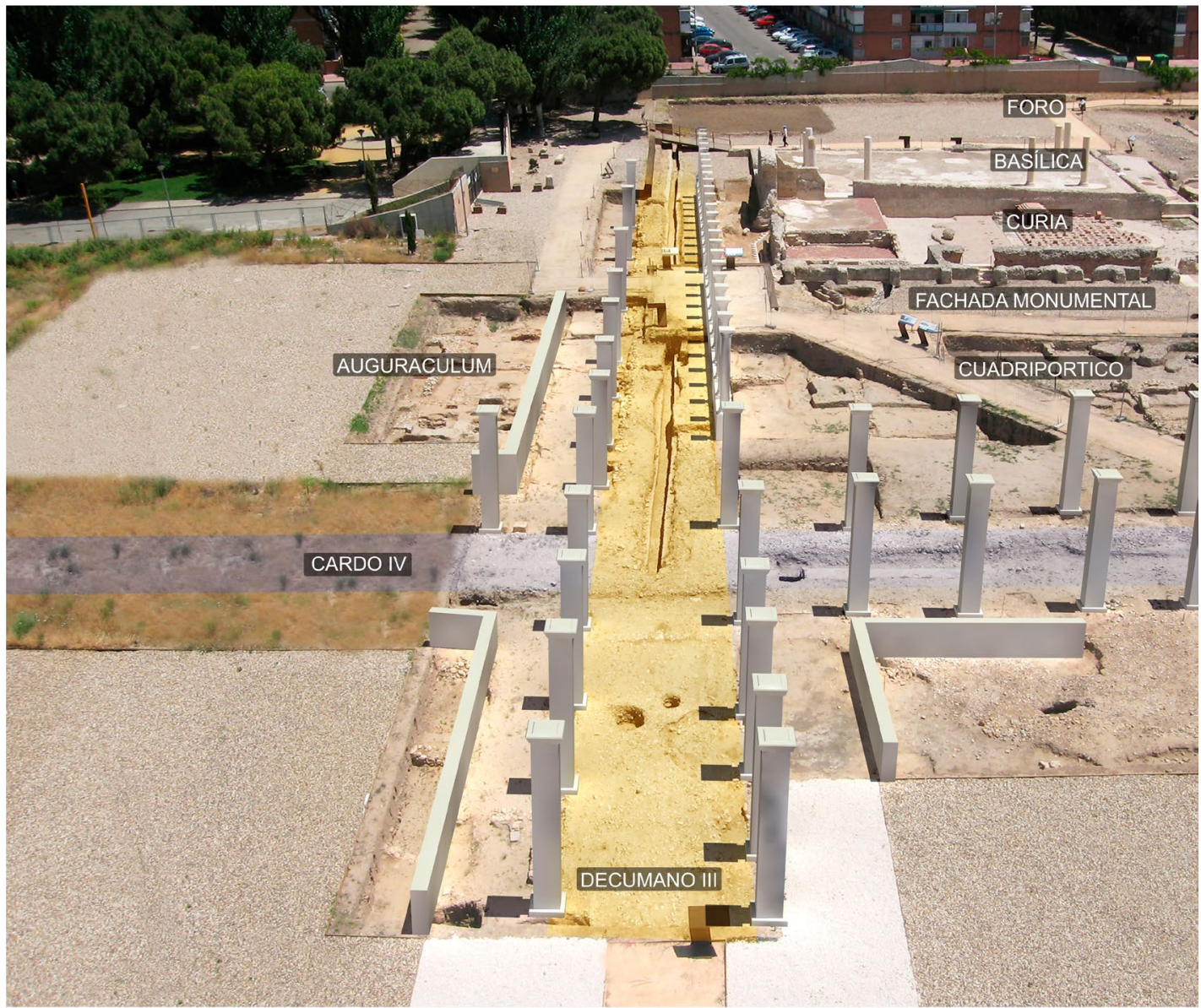

Figura 3: Estructura de calles porticadas de Complutum, ejemplificada en el decumano III. 
modulación, ocupando $c .1 \times 2$ actus (35 $\mathrm{m}$ de anchura por $67,5 \mathrm{~m}$ de longitud) ${ }^{1}$.

Con respecto a las calles (Rascón Marqués y Sánchez Montes: 2015) se ha constatado la existencia de calles principales con una anchura de $12 \mathrm{~m}$ (es decir, 40,5 pies, como el caso muy bien documentado del decumano III), y con una estructura consistente en un pórtico de anchura levemente inferior a $3 \mathrm{~m}$ a cada lado de la calle, y entre ambos la calle propiamente dicha, de c. 6 m (Fig. 3). Sin embargo la investigación ha probado la existencia de ciertas alteraciones, en torno a los edificios públicos o en «calles secundarias» de sólo $8 \mathrm{~m}$ de anchura (así, el cardo IV). Puede afirmarse que el programa urbanístico general albergaba la existencia de pórticos en casi todas las calles, mediante pilares de piedra con plinto, fuste y capitel, y con soluciones particulares para edificios singulares (así, el conjunto de edificios públicos en general).

Los datos más precisos (prospecciones geofísicas y excavaciones arqueológicas) que avalan esta hipótesis pertenecen sobre todo a la regio II y a la III. Son en cambio más escasos en la V y la VI, dos barrios de la ciudad romana que se encuentran enterrados bajo barriadas modernas desde la década de 1970; pero aun así, los datos que existen en estas dos regiones, principalmente procedentes de excavaciones muy puntuales, sobre todo relacionados con la arqueología preventiva en Alcalá de Henares, apuntan grandes semejanzas con II y III. En cambio en la regio I y en la IV, no existen datos $\mathrm{o}$, en algunos puntos, existen algunos que son difíciles de interpretar: por ejemplo, los que proceden de excavaciones anteriores a 1900 de las que apenas existe documentación, y sugieren unas características arquitectónicas distintas al estándar que conocemos en II y III: edificios que se orientan con un eje diferente, y/o que tienen una superficie de módulo distinto a la general de $30 \times 30 \mathrm{~m}$.

\section{LOS PROBLEMAS DE INTERPRETACIÓN EN LA REGIO IV}

Existe por tanto una hipótesis bastante sólida sobre este diseño urbano general, pero hasta la fecha se carecía de datos precisos referidos al cuadrante Noroeste de la ciudad, que principalmente se corresponde con la zona denominada regio IV. El objetivo de la investigación que se presenta en este trabajo era precisamente dilucidar las características generales del diseño urbano en este sector.

En la regio IV, que tendría una extensión aproximada de 8 ha (si bien no toda la superficie era

\footnotetext{
1. Debe advertirse que con los datos actuales está sin resolver la modulación exacta del foro. La hipótesis vigente sobre los edificios públicos se expone en Rascón y Sánchez Montes, 2009. Pero las investigaciones de los últimos años, sin contradecirse con ella, apuntan sin embargo a un panorama aún más complejo.
}

accesible), nos enfrentábamos por tanto a una difícil interpretación: había algunos, pero muy pocos, restos arqueológicos excavados con metodología moderna, únicamente en la llamada zona de la fuente del Juncal y sobre una superficie muy limitada, aproximadamente $3.500 \mathrm{~m} 2$; también una fuente histórica (la misma fuente del Juncal), de claro origen romano, aunque con una fisonomía que data de varias reformas que se remontan al siglo XVI, pero sobre todo alterada por una drástica reforma del XIX; todo ello situado en el extremo occidental de la regio. Por otra parte, existen varias referencias a excavaciones desarrolladas a lo largo del siglo XIX, excavaciones de bastante alcance (y donde se documentaron calles, zonas sepulcrales y varios edificios, muy probablemente casas y almacenes) pero que han dejado una documentación escasa y poco precisa: especialmente, una serie de croquis de los años 1893, 1894 y $1897^{2}$ (Fig. 4). Si además consideramos que la regio IV se encuentra actualmente dentro de las zonas del yacimiento preservadas, y casi completamente libre de construcciones modernas, parecía que era posible desarrollar una investigación en profundidad para dilucidar las características del diseño urbano de esta parte de la ciudad romana. Igualmente, dada la extensa superficie de la regio IV, parecía evidente que, además de revisar la documentación ya citada, la metodología del trabajo debía incluir una prospección geofísica, por ser este el único recurso para obtener una información relativamente precisa sobre una extensión de terreno muy amplia.

\section{PLANTEAMIENTO DE LA PROSPECCIÓN GEOFÍSICA}

Como es sabido, la prospección geofísica aplicada a la arqueología es un término amplio que engloba un conjunto de técnicas científicas que permiten la detección de restos enterrados en el subsuelo de la superficie terrestre. Desde mediados del siglo XX (Hesse, 2000; Gaffney y Gater, 2003), geofísicos y arqueólogos han desarrollado de forma interdisciplinar una serie de técnicas geofísicas para resolver problemáticas específicas para la arqueología, tanto en lo que se refiere a la detección y localización de yacimientos arqueológicos enterrados, como evaluar su potencialidad y determinar otro tipo de acciones antrópicas antiguas. El objetivo es presentar una imagen, lo más clara posible de las anomalías registradas en el subsuelo, mediante la aplicación de la geofísica y las correcciones informáticas correspondientes. Comparable a la imagen que pueden producir una pantalla de rayos X, pero en este

2. La mayor parte del material disponible de aquellos años se encuentra en los así llamados «papeles Saldaña», recopilados por este investigador local a lo largo de su vida, y publicados más tarde por Vallejo, 2005, gracias a la cortesía de la familia de aquel. 


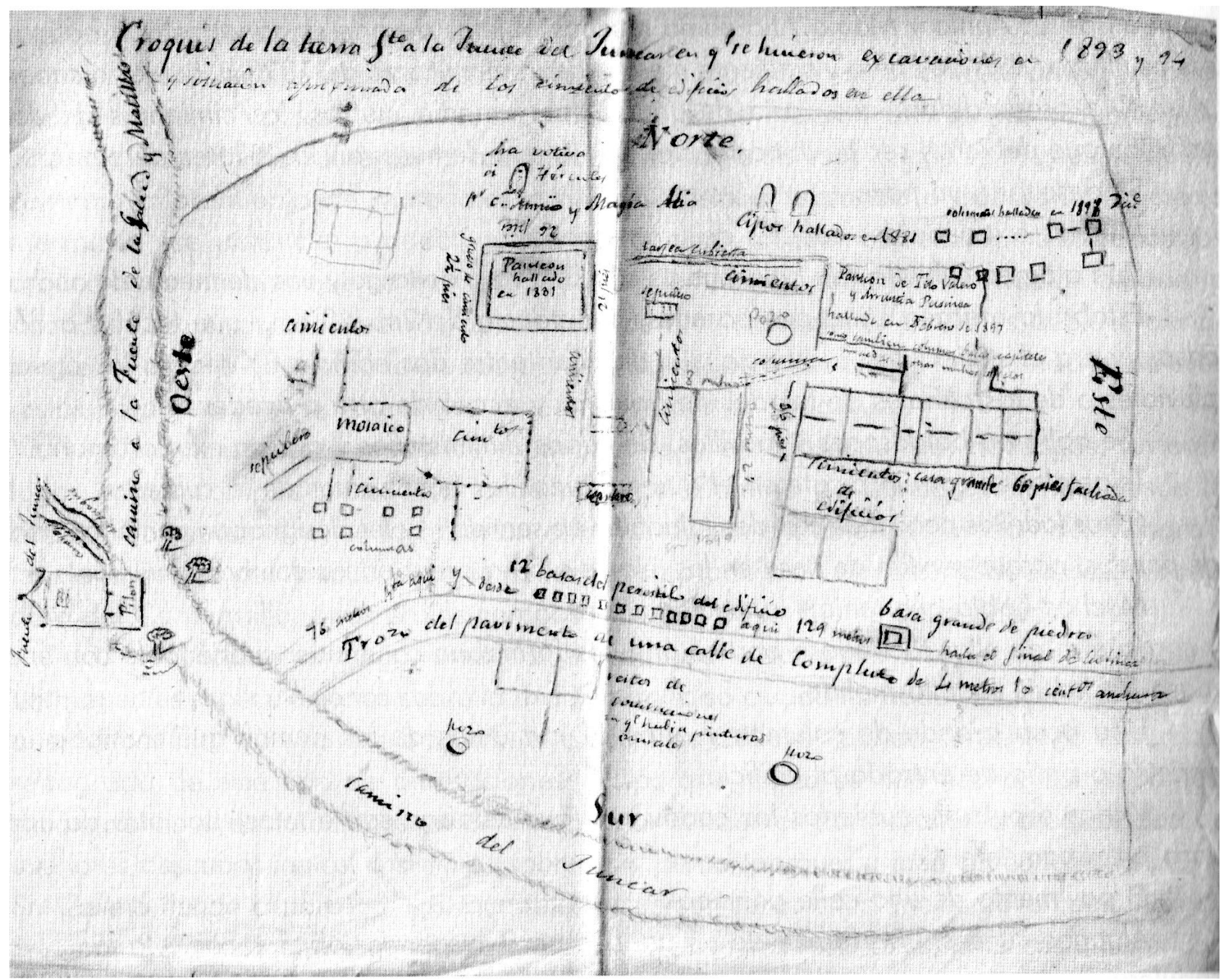

Figura 4: Croquis de las excavaciones de 1893, 1894 y 1897 (Vallejo, 2005: 156).

caso aplicada a la superficie terrestre a una profundidad de apenas unos metros. En algunos casos, las alteraciones de las propiedades del subsuelo responden a restos arqueológicos, y resulta sencillo interpretarlas como elementos de un yacimiento arqueológico - muros, depósitos, cloacas, silos, fosas...; en otros casos responden a estructuras naturales o intervenciones humanas modernas.

Incluso las alteraciones antrópicas detectadas por la geofísica pueden pertenecer a diversos períodos históricos, e intervenciones arqueológicas modernas. El caso de la prospección de la regio IV de Complutum es paradigmático porque disponemos de información sobre los trabajos arqueológicos en este solar ya desde el siglo XIX. A pesar de que los croquis de las excavaciones de 1893, 1894 y 1897 no son muy precisos (Vallejo, 2005: 156), aportan una información útil para la interpretación de las anomalías detectadas, y pueden ser un eficaz complemento para su interpretación.

Así, en mayo de 2012 el Servicio Municipal de Arqueología de Alcalá de Henares (SMArq) y el Institut Català d'Arqueologia Clàssica (ICAC) diseñaron una prospección geofísica eléctrica en la regio IV, desarrollada por Cèsar Carreras, Pau Olmos y Pau De Soto, con la participación de Sebastián Rascón y Ana Lucía Sánchez, directores de las intervenciones arqueológicas de Complutum.

El espacio para la prospección era un descampado suburbano, totalmente plano y con escasa vegetación, que durante tiempo se había utilizado como aparcamiento improvisado. La extensión total prospectada por resistividad comprendía 32 cuadros de 30x30 m, o sea unos $28.800 \mathrm{~m}^{2}$, casi 3 ha.

A pesar de la imposibilidad de situar con precisión los croquis de excavaciones decimonónicas contenidos en los «archivos Saldaña», puede afirmarse que, en general, el espacio en que se ubicó la prospección geofísica se situaba al Este de aquellas, de forma que en parte coinciden topográficamente, pero otra parte importante de la superficie prospectada no coincidía con zonas alteradas en el XIX, sino que se sitúa más a Oriente.

Inicialmente se escogió el mes de mayo por tratarse de un mes primaveral en que el terreno acostumbra a estar bien drenado. No obstante, durante los diez días que duró el trabajo de campo, las condiciones variaron 
completamente y se alcanzaron altas temperaturas, que afectaron también a la humedad del suelo. Los trabajos de campo se desarrollaron finalmente entre el 10 y el 18 de mayo de 2012 .

A finales de mayo y principios de junio del 2013 se acometió la prospección de 6 cuadros de 30x30 m situados al sur del foro, estos ya en una zona distinta $y$ alejada de la regio IV que ahora nos ocupa. Se trataba de una zona que no se había podido prospectar en su momento por la excesiva sequedad del suelo y la presencia de materiales de construcción en la superficie, y cuyos datos no van a emplearse en el objeto de este trabajo.

\section{ANTES DE LA PROSPECCIÓN: ESTUDIOS PRELIMINARES DEL YACIMIENTO}

Las condiciones geofísicas que se pueden encontrar en Alcalá de Henares son las típicas de las Meseta, con inviernos fríos y secos y veranos muy calurosos. Por esa razón, era muy importante seleccionar bien una estación húmeda para realizar la prospección eléctrica para que los suelos estuvieran suficientemente drenados para que hubiera una buena conductividad eléctrica, y fuese sencillo detectar las anomalías o resistencias. En principio, las fechas eran adecuadas, si bien como ya hemos comentado, debido a las fuertes temperaturas, el suelo fue perdiendo rápidamente humedad, por lo que estaba bastante seco en los últimos días.

Al ser un descampado suburbano con uso extensivo por parte de los vecinos desde hace muchos años, gran parte del solar presentaba numerosos restos de plásticos y material metálico que dificultaba el uso de determinados métodos de prospección. La magnetometría se debía descartar por la presencia de los restos metálicos, y por experiencias negativas llevadas a cabo en otras zonas del yacimiento. Concretamente había sido probada sin éxito en la prospección realizada por A. Kermorvant, de la Universidad de Tours, en 2000 (Kermorvant y González, 2000-2001). También parece que ha habido experiencias negativas en el uso de GPR, pero al menos desde nuestra perspectiva, puede que sea un método útil y compatible a la resistividad utilizada en la regio IV. Debido a estos resultados negativos tanto de la magnetometría como del GPR, en otras partes del yacimiento próximas, se decidió apostar por la resistividad.

Por lo tanto, se decidió utilizar la resistividad como método en base a los positivos resultados obtenidos con anterioridad en otras zonas de Complutum, muy especialmente la regio II. En el solar a prospectar, el método parecía adecuado, y tal como aparece en la figura 5 , la vegetación no representaba ningún problema. Era una vegetación escasa y corta, no molestaba en el movimiento de los prospectores y los cables, a excepción de algunas zonas reducidas donde la vegetación era más abundante y frondosa dificultando sensiblemente el trabajo de campo.

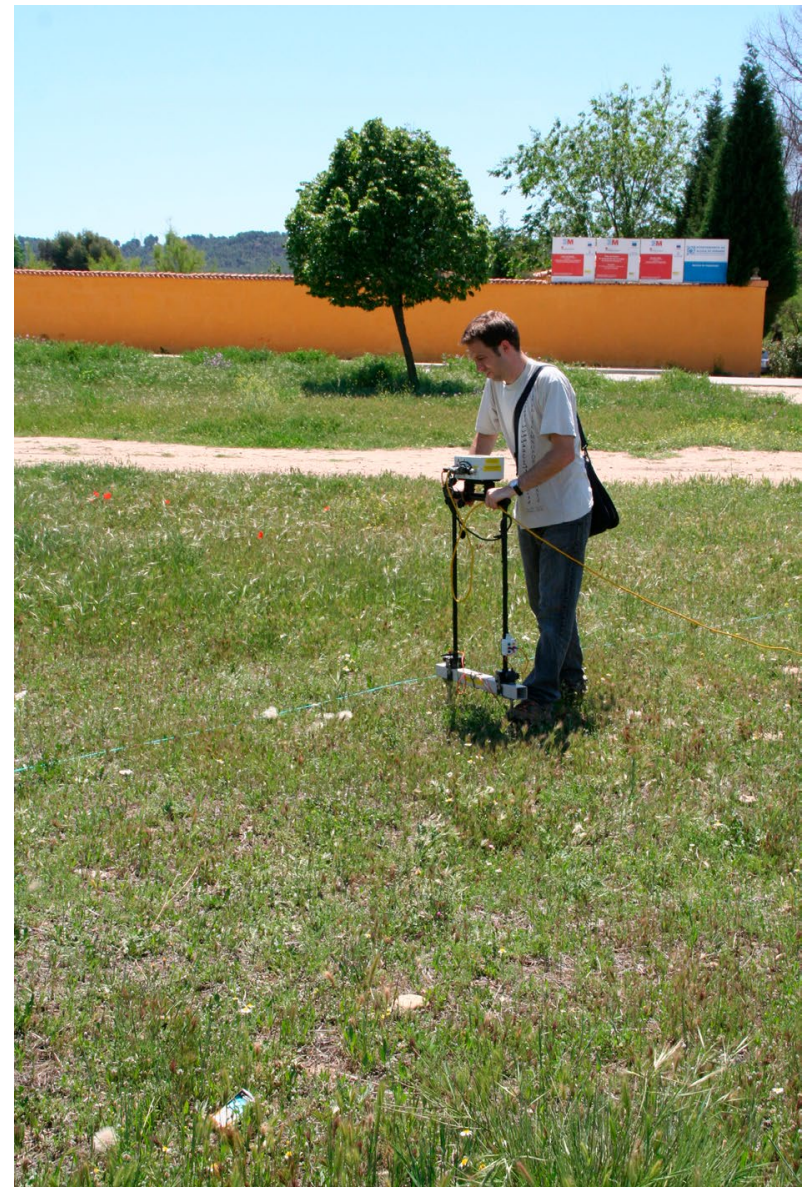

Figura 5: Zona prospectada con restos de escasa vegetación.

\section{SuElos}

El tipo de suelo es también un factor determinante a la hora de escoger los métodos geofísicos utilizados en la prospección. En el caso de Complutum, se trata de suelos sedimentarios aluviales, que conservan muy bien la humedad y facilitan en general el uso de la prospección eléctrica por resistividad. Tal como se ha venido comprobando en esta prospección, las condiciones climatológicas pueden alterar substancialmente las condiciones de humedad de los suelos. De todas formas, al tratarse de un parque urbano, algunas zonas del solar presentan anomalías debido a usos modernos del mismo. Por ejemplo, existen una serie de caminos de tierra, algunos de ellos incluso con restos de antiguos asfaltados, que presentan altas resistencias ya que el terreno está más compactado, y por lo tanto, tiene un menor drenaje y preserva menos la humedad, y de esta manera limita la conductividad eléctrica. Incluso actualmente, existe una parte sin vegetación, en la que ocasionalmente transitan vehículos e incluso llegan a aparcar temporalmente. En la zona Este, existe un parking asfaltado en superficie, que ha sido nuestro límite de prospección puesto que los electrodos móviles no pueden clavarse en esta superficie.

Por otro lado, parece que hasta la década de 1990 gran parte del solar fue utilizado como basurero, lugar 
de parking y también para realizar cambios de aceite, por lo que perviven restos de estas actividades que nos han proporcionado algunas anomalías extrañas, coincidiendo con cuadros de prospección muy concretos.

Otra alteración de los suelos la han provocado las antiguas excavaciones arqueológicas realizadas en el solar a finales del siglo XIX, y que en su momento identificaron una serie de estructuras y restos de pavimentos, y cuyo destino final se desconoce. Dado que el terreno hoy en día es básicamente una planicie, imaginamos que en cierto momento se volvieron a cubrir para propiciar un uso agrícola, quizá no sin antes sufrir un severo expolio. También estos rellenos han alterado la consistencia de los suelos, por lo que crean anomalías geofísicas que entendemos que están identificando las catas arqueológicas realizadas en el siglo XIX.

Vallejo (2005) ha realizado un estudio de todas las evidencias sobre estas intervenciones antiguas, de las que disponemos algunos dibujos de piezas, brevísimos diarios y algunos croquis orientativos, sin el suficiente detalle como para ayudarnos en la interpretación de las anomalías geofísicas. Aún así, se han tenido en consideración, para posicionar alguno de los ejes y edificios singulares.

\section{CONDICIONES ARQUEOLÓGICAS}

Las condiciones arqueológicas del yacimiento de Complutum son adecuadas para la prospección geofísica, tanto por la humedad del suelo como por los restos arqueológicos ya documentados de muros de piedra y pavimentos de signinum y mosaico. Aunque no tenemos constancia de la profundidad a la que se pueden encontrar los restos, seguramente gran parte de ellos están a menos de $2 \mathrm{~m}$ de profundidad, por lo que se han podido localizar anomalías claras.
Partimos además de la información obtenida en otra prospección geofísica, a partir de la cual se ha confeccionado una propuesta de planta ortogonal para el yacimiento de Complutum (Rascón Marqués y Sánchez Montes, 2014b). Esta hipótesis está sólidamente fundada para las regiones I, II y III, pero se ha proyectado, a falta de la disposición de más datos, sobre la IV. A partir de los resultados obtenidos en nuestra prospección, parece que algunas de las anomalías, si bien coinciden con la orientación del urbanismo de la ciudad, sugieren ciertas variaciones en el módulo de manzanas propuestas en la hipótesis inicial.

Otro aspecto interesante es el límite entre la zona urbana y el exterior de la ciudad, en la cual ya se han documentado algunos restos de tumbas y mausoleos, en la que podría ser una ronda circundando a la ciudad. Definir este límite de la ciudad, y posible circunvalación de la misma con una muralla. Estas posibles anomalías se deberían localizar en la zona norte del área de prospección, y era otra de las hipótesis que se debía contrastar.

Como se indica al hablar de los suelos, las excavaciones del siglo XIX y el posterior relleno de las zonas excavadas con cascotes y tierra, han modificado substancialmente el subsuelo, por lo que existen unas zonas con valores muy altos en la resistividad. Estas anomalías, marcadas en la figura 6 con valores en rojo, se concentran en cuadros muy concretos del área excavada.

\section{MÉTODOS DE PROSPECCIÓN}

Inicialmente se pensó que hubiera sido interesante combinar una serie de métodos geofísicos para tener una imagen más completa de las anomalías del yacimiento. Se creía que además de la resistividad, la
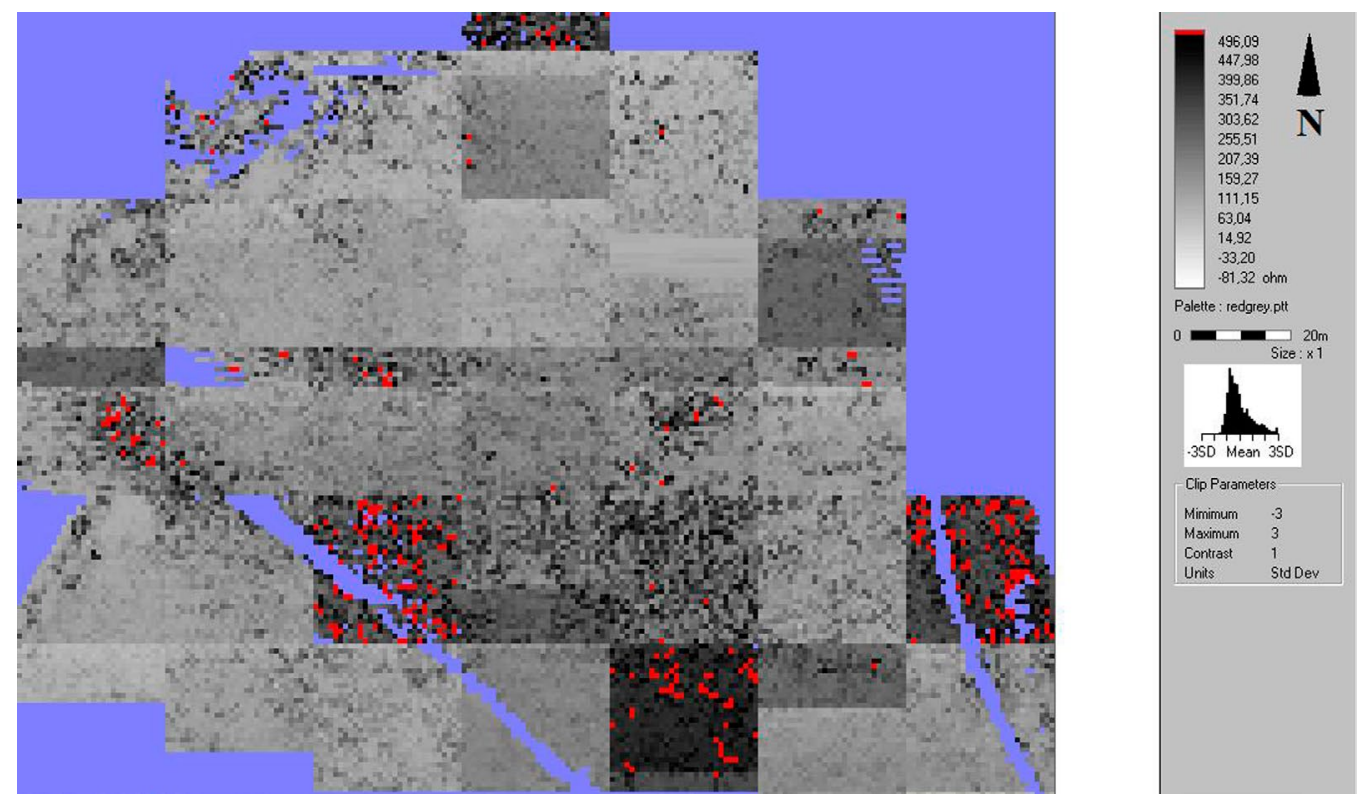

Figura 6: Anomalías con valores altos de posibles intervenciones antiguas. 
magnetometría hubiera sido un método complementario de prospección, si bien los resultados negativos anteriores no recomendaban su uso. Finalmente, no se dispuso del equipo para realizarla.

Así pues, se realizó una prospección eléctrica en la zona de mayor extensión con un Geosan RM-15-D con unos electrodos móviles situados a una distancia de $50 \mathrm{~cm}$ entre sí, que nos proporcionaba lecturas de una profundidad de 1,5-1 m, o incluso un poco más.

\section{PROSPECCIÓN ELÉCTRICA - RESISTIVIDAD}

La resistividad eléctrica es una técnica apropiada para reconocer contrastes en el subsuelo debidos a retenciones de agua o concentraciones de iones disueltos (Weymouth, 1986; Carreras, 2013). El estado del suelo y su grado de compactación también son variables a tener en cuenta, que incluso pueden estar afectadas por las condiciones climáticas extremas (por ejemplo, sequía o helada). Cuanto más húmedo está un suelo, más facilita la conducción eléctrica, y por tanto, menos resistencia supone. A nivel arqueológico, la disposición de los electrodos móviles (entre 0,5 y $2 \mathrm{~m}$ ) indica el nivel de profundidad de la lectura. Por ejemplo, una separación de $0,5 \mathrm{~m}$ entre electrodos proporciona lecturas hasta a 1-1,5 m, cuando es de $1 \mathrm{~m}$ proporciona entre 1,5-2 m y 1,5 a 2,5-3 $\mathrm{m}$. La resistividad detecta estructuras arqueológicas muy diversas como pueden ser construcciones de piedra (muros, fundamentos, pavimentos), estructuras excavadas y rellenadas (fosas, trincheras), tierra compacta (vías, calles), etc...

\section{INSTRUMENTAL}

Para llevar a cabo la prospección eléctrica se ha empleado un resitivímetro (RM15-D) de Geoscan, que permite sistemas de pruebas múltiples, y que puede incorporar un MPX15 Multiplexer con el cual se pueden realizar tres lecturas simultáneas con tres pares de electrodos móviles a distancias de 0,5, 1 y 1,5 m. El aparato permite todo tipo de combinación de electrodos y configuraciones, aquí se ha empleado la configuración de twin-pole.

En el caso concreto de Complutum, el aparato tenía los electrodos móviles dispuestos únicamente a una distancia de $0,5 \mathrm{~m}$ y fijos, para cubrir más rápidamente la extensión, y puesto que los resultados ya nos proporcionaban datos a una profundidad de 1-1,5 m.

\section{LECTURAS}

La prospección eléctrica se ha realizado en un único sector en el solar anexo al camino del Juncal, que lleva hasta la fuente del mismo nombre. Se considera que el mismo camino del Juncal podría ser un eje fosilizado de un antiguo decumano de la ciudad romana de
Complutum. En todo este solar se han prospectado un total de 32 cuadros de $30 \times 30 \mathrm{~m}$, cubriendo un total de unos $28.800 \mathrm{~m}^{2}$, casi 3 ha. Actualmente se acepta que las campañas geofísicas necesitan una extensión mediana o grande para ofrecer unos resultados interpretables óptimos (5 ha; ver Keay et alii, 2009). De este modo, el área prospectada, de casi 3 ha, asegura ofrecer un marco espacial óptimo para la interpretación de las anomalías y la detección de posibles estructuras urbanas.

De hecho, la zona propuesta para prospectar era aún mayor, pero debido a la respuesta geofísica de las áreas de los extremos, en que había numerosas anomalías modernas (los ya citados caminos de tierra, zonas de aparcamiento improvisado...), se decidió no prospectar estos cuadros.

\section{Procesamiento DE LOS DATOS}

Los datos obtenidos con el RM-15-D han sido inicialmente tratados con el programa Geoplot, que incorpora el propio equipo de resistividad de la empresa Geoscan. Dentro del propio programa se crean todos los cuadros, y se realiza una primera mejora de la imagen con el uso de filtros. Se utiliza primero de todos el filtro Despike, que elimina los valores extremos seguramente debidos a errores del operador durante la prospección. Estos valores son substituidos por un valor medio de las lecturas adyacentes.

En segundo lugar se ha utilizado el filtro Low Pass que ha mejorado la definición de algunas de las anomalías permitiendo una mejor interpretación. Con la imagen obtenida por este filtro ya hemos procedido a la interpretación de las anomalías. Y finalmente, también se ha aplicado, cuando se ha creído conveniente, el filtro High Pass.

Si bien la imagen conjunta de toda la prospección ya proporcionaba algunas anomalías claras, la variabilidad en valores y condiciones aconsejó analizar cada zona de forma separada, agrupando los valores similares y reclasificando valores extremos a partir de los resultados proyectados en los histogramas.

Finalmente, para obtener una mayor flexibilidad en el análisis, se han exportado todos los valores de los cuadros prospectados en formato XYZ al programa SNUFFLER, desde el cual se ha llevado a cabo un análisis pormenorizado aplicando de nuevo filtros.

\section{RESULTADOS E INTERPRETACIÓN}

Las imágenes de la prospección eléctrica de resistividad han proporcionado un número significativo de anomalías que siguen una pauta ortogonal que claramente se deben vincular al urbanismo de la ciudad y el módulo de las manzanas o insulae que, en general, se han propuesto para las otras regiones, y particularmente la II y la III. Igualmente, proporcionan datos de 


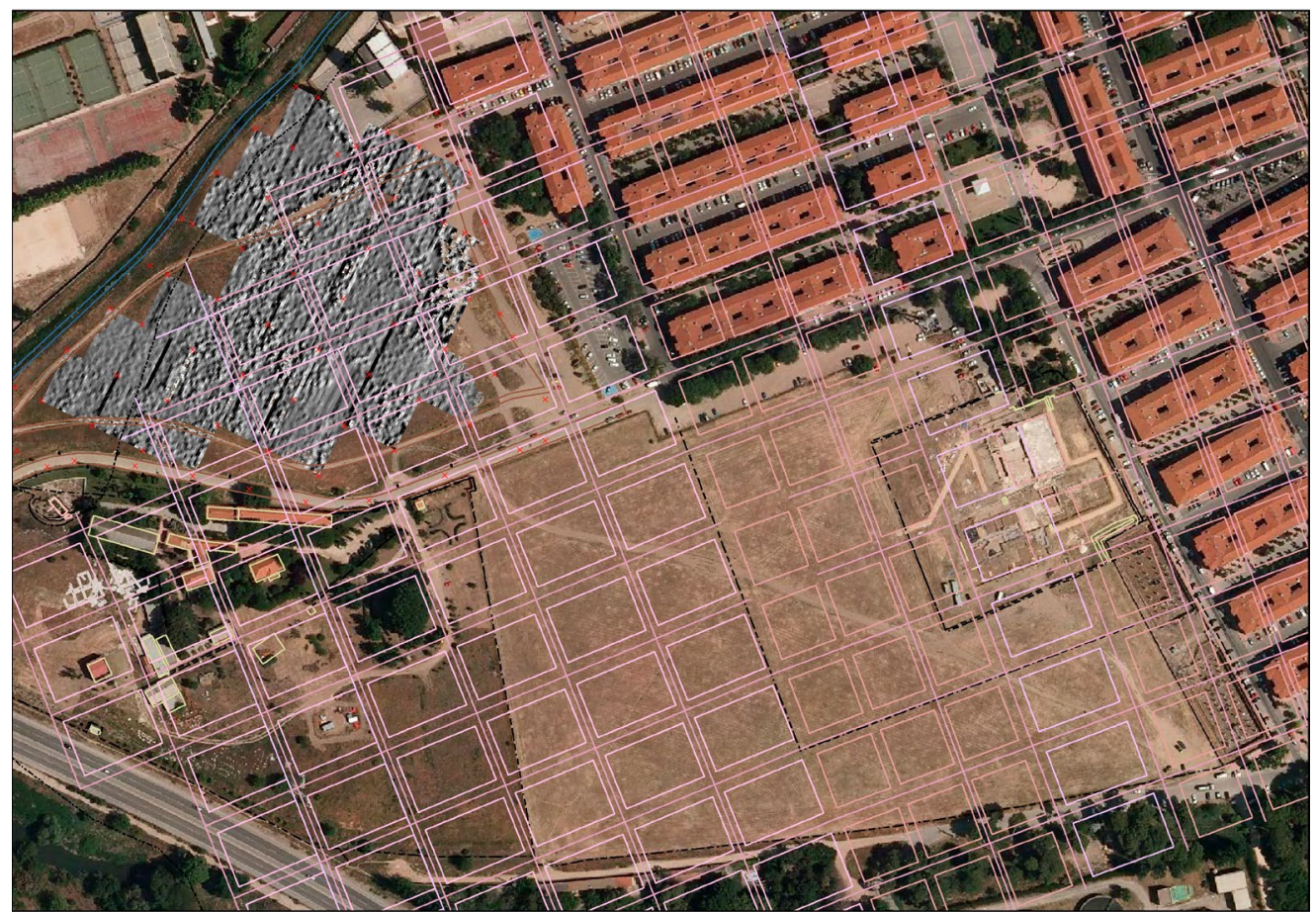

Figura 7: Imagen de la geofísica proyectada a la hipotética división urbanística.

un edificio singular en el extremo oriental de la superficie prospectada.

\section{RESULTADOS DE LA RESISTIVIDAD}

La interpretación de las anomalías positivas (alta resistividad) lineales parecen delimitar algunos de los muros que definen las principales vías, así como divisiones internas de las manzanas o insulae (Fig. 7). Si bien las divisiones en insulae son claras, y presentan (con excepciones) una superficie de tendencia cuadrada. Esta estructura urbanística difiere de la hipótesis de partida que ilustraba la figura 2 , con unos módulos de forma rectangular.

En los ejes NE-SO, correspondientes a los cardines de la estructura urbana de la ciudad, se observa que la orientación es casi coincidente con la hipótesis anterior a la prospección, y marcada por líneas rosadas. Pero los cardines no coinciden con la situación topográfica de esta última, lo que parece deberse a que las manzanas que hemos documentado en nuestra prospección no se ajustan al formato rectangular sobre el hipotético eje E-O que a priori se suponía, sino a un formato cuadrado de $30 \times 30 \mathrm{~m}$, por otro lado el más extensamente documentado en Complutum. Si se observa con detenimiento la propuesta urbanística original, así como su proyección en la zona prospectada, no acaban de coincidir las anomalías geofísicas de la regio IV con el módulo de insula rectangular. Por el contrario, las anomalías lineales parecen corresponder a un módulo más pequeño, próximo al módulo cuadrado que está bien documentado en la regio III y, muy especialmente, en la II (de nuevo figura 7).

Aparte de las líneas rojas con anomalías, se observan otras alteraciones con altas resistencias concentradas principalmente en dos sectores de la superficie prospectada (Fig. 8). Por un lado, en la parte meridional; por otro, en la zona nororiental del espacio objeto de la prospección. Carecemos de planimetrías más detalladas. La explicación más plausible, a falta de conocer más datos, es que estas alteraciones se correspondan con zonas excavadas el siglo XIX, que posteriormente fueran rellenas con material constructivo del propio yacimiento. Hay que considerar que las excavaciones del siglo XIX no parecen haber albergado ninguna intención conservacionista sobre los restos arqueológicos del yacimiento. Teniendo en cuenta que tradicionalmente el solar era una gran zona de cultivo, cabe suponer que haya existido una tarea de tapado de desniveles y sondeos, utilizando la propia tierra del sitio y con el material constructivo incorporado. Por desgracia, las características de la documentación del siglo XIX, en las que existen solo referencias topográficas relativas, y solo en el caso de los restos más singulares, imposibilita que podamos identificar con claridad anomalías determinadas de la resistividad con restos concretos exhumados en esa época. Además, los croquis de los «archivos Saldaña» que estamos manejando no reflejan en modo alguno la totalidad de las excavaciones que se produjeron en Complutum antes del siglo XX, y que debieron ir mucho más allá de las búsquedas de Guerra Berroeta y José Demetrio Calleja. Con lo cual puede haber sectores de esta regio que hayan sido objeto 


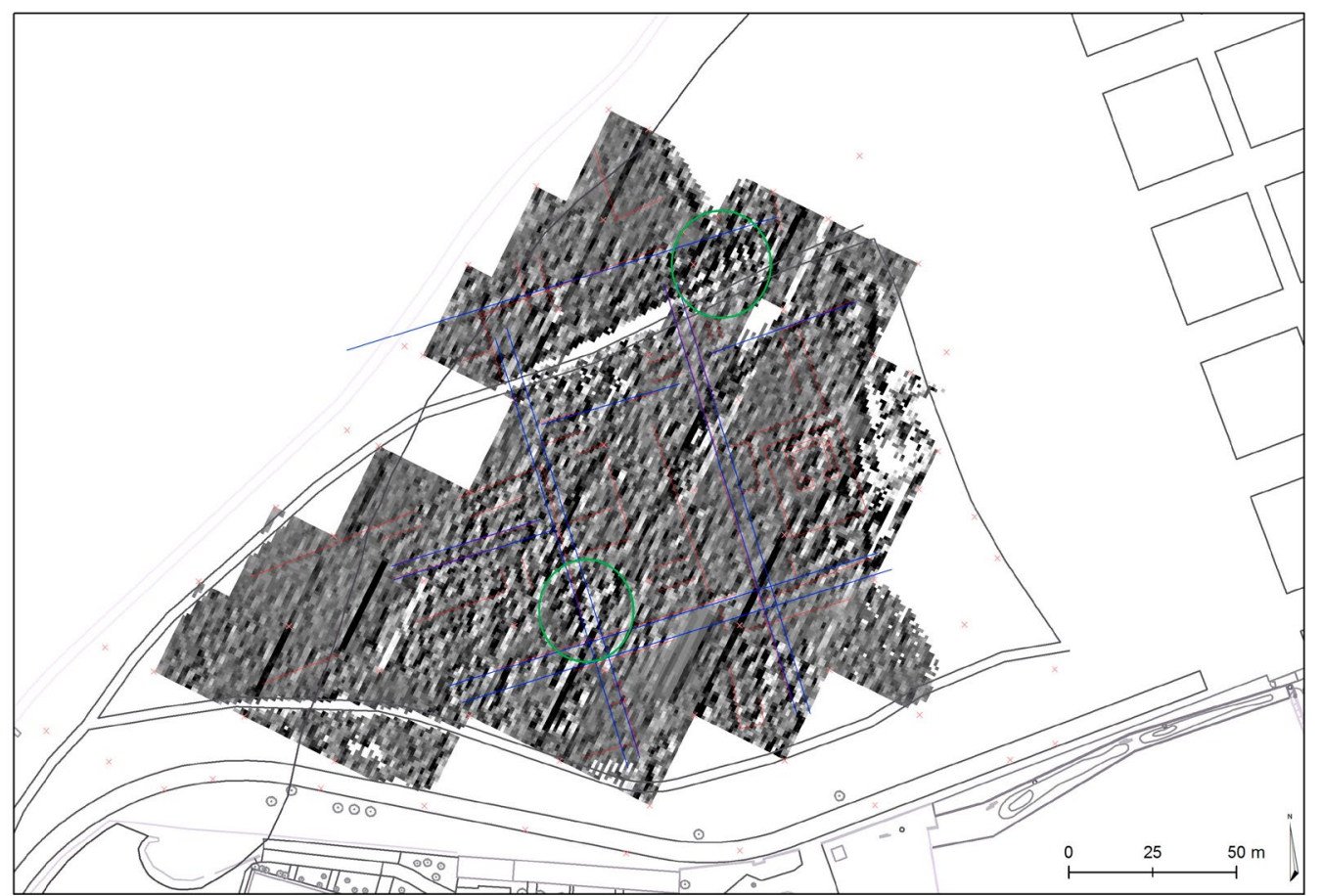

Figura 8: Imagen compuesta con la interpretación de las anomalías de resistividad. En verde dos zonas con anomalías irregulares de posibles excavaciones antiguas.

de excavaciones intensas, y de las que no tengamos constancia documental.

Parte de las anomalías positivas (altas resistencias) definen las fundaciones de piedra de muros exteriores que delimitan las calles, y también los muros internos de los distintos edificios dentro de las manzanas. Algunas de las divisiones internas parecen reflejar habitáculos de planta cuadrada o rectangular de menos de 10 $\mathrm{m}$ de lado, que recuerdan a estructuras documentadas en el área nordeste de la zona excavada en el siglo XIX.

Por otra parte, también se observan valores altos en el medio de las posibles calles, lo cual puede interpretarse como las anomalías generadas por las cloacas (specus), de grandes dimensiones que son visibles en todo el yacimiento y están bien estudiadas en la regio II (Rascón Marqués y Sánchez Montes, 2013).

La principal novedad aportada por la prospección ha sido la identificación de un espacio singular rectangular que rompe la ratio de manzanas de 30x30 $\mathrm{m}, \mathrm{y}$ adquiere la correspondencia de un modulo de 1' $5 \times 1$, es decir de unos $45 \mathrm{~m}$ de largo por unos 30 $\mathrm{m}$ de ancho, albergando en su interior una estructura rectangular, casi cuadrada, de entre 10 y $15 \mathrm{~m}$ de longitud, y orientado en sentido dirección Norte-Sur (Figs. 9 y 10). Las trazas son bastante claras, en una zona que según la documentación antigua no se había llegado a excavar, y por lo tanto resta inalterado. Con las debidas precauciones, la forma de esta anomalía parece recordar la estructura característica de un santuario urbano: por un lado un temenos o quizá un plinto delimitado por un muro exterior que sería el rectángulo de $45 \times 30$ metros, y en el interior

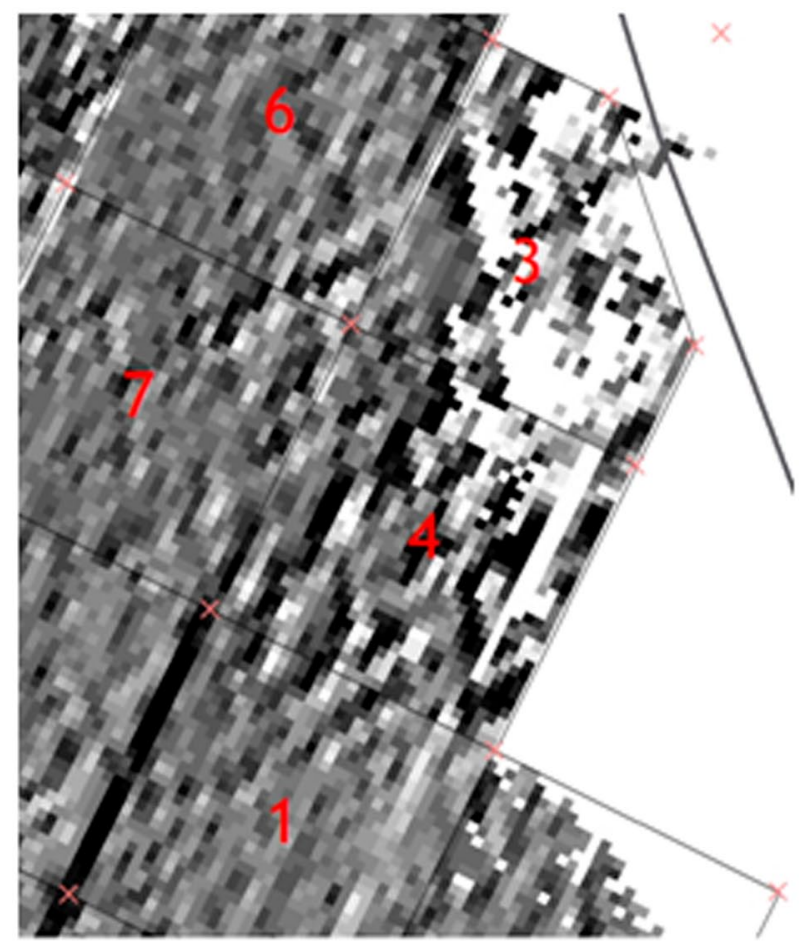

N

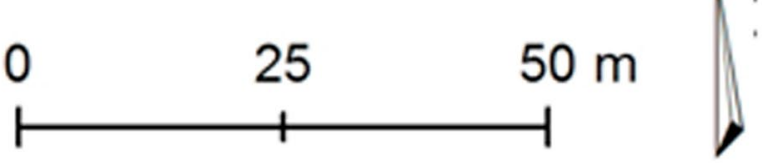

Figura 9: Anomalías mostrando posibles trazas de un edificio singular al Este de la regio IV. 


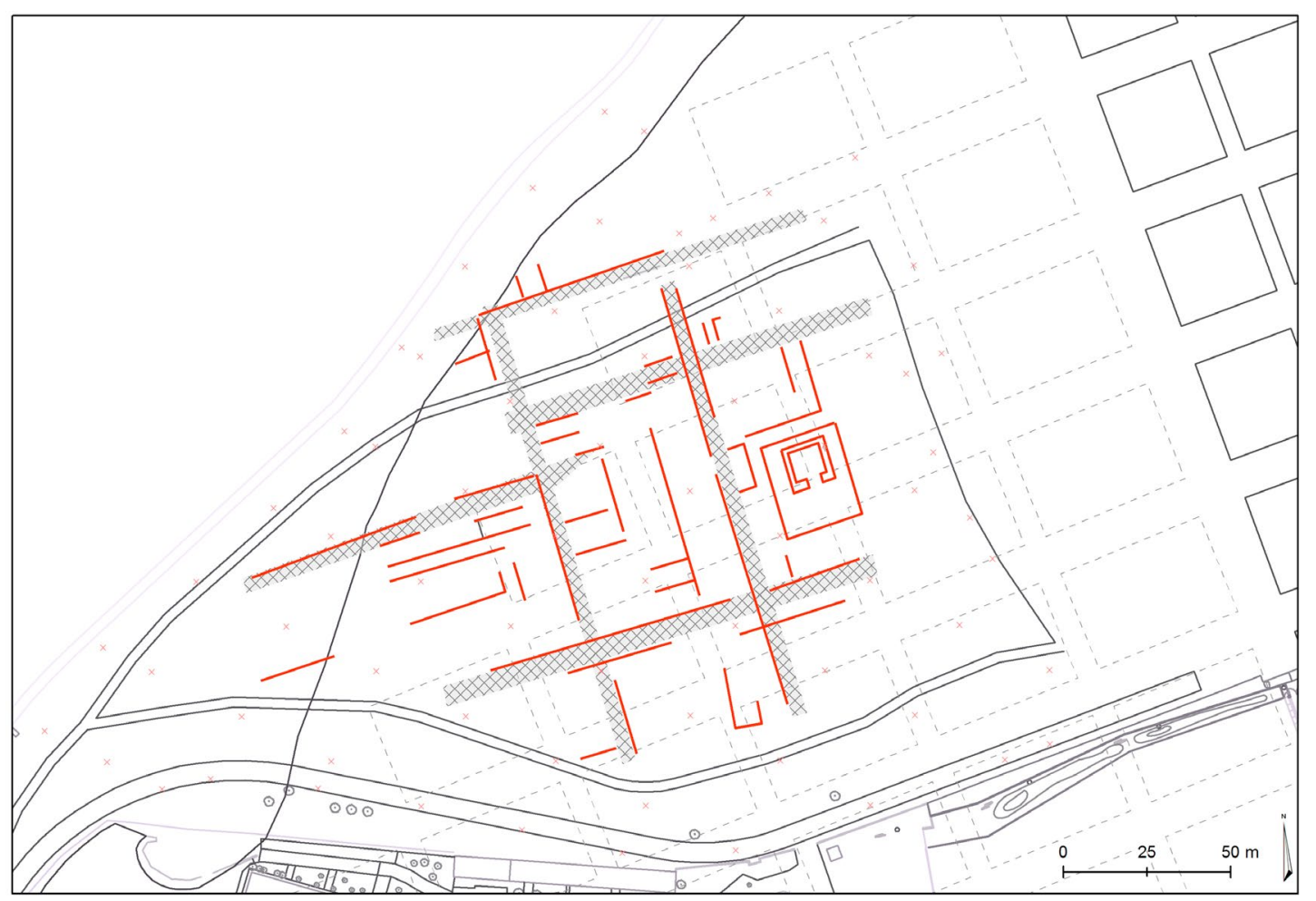

Figura 10: Interpretación de las posibles trazas del edificio singular.

un posible espacio de culto, una cela de estructura rectangular.

\section{LECTURA URBANíSTICA DE LA REGIO IV}

En lo que se refiere al diseño urbano, y a la luz de los resultados obtenidos, es conveniente plantear una nueva propuesta urbanística para la regio IV. Esta propuesta ha de seguir un único módulo cuadrado similar al propuesto en las regiones restantes, especialmente la II y la III (Fig. 11). Sin embargo, hemos de dejar un cierto margen de incertidumbre, pues los edificios documentados mediante excavaciones arqueológicas junto a la fuente del Juncal en varias campañas, la última en 2010, muestran un módulo cuadrado inferior a los 30x30 m. Son espacios de la regio IV, pero topográficamente alejados de nuestra zona de prospección, y cercanos en cambio a la entrada occidental de la ciudad. Concretamente, el único edificio que ha podido medirse en toda su extensión, y que estaría al Norte del decumano máximo, calle a la que se abriría su fachada meridional, mide aproximadamente $15 \times 17$ $\mathrm{m}$. Pasamos no obstante a describir los principales elementos que definen el urbanismo de este sector de Complutum.

En primer lugar, los elementos constructivos monumentales. Dos de ellos se conservan in situ: en el extremo occidental, los restos de lo que, con las debidas precauciones, consideramos un tetrapylon (Rascón Marqués y Sánchez Montes, e.p.) que marca el eje del decumano máximo, descubierto en las excavaciones de 2012, y conservado tan sólo a nivel de su cimentación de opus caementicium. Edificio excepcional por su rareza, este arco de cuatro frentes serviría para marcar el acceso a la ciudad, y al Norte de la línea del decumano que lo atraviesa se desarrollaba la regio IV. Somos conscientes de la rareza (aunque no excepcionalidad) de un edificio de estas características en Complutum, y concretamente en el extremo de un vial, dado que este tipo de monumento no es frecuente en Hispania, y además suele hallarse en posiciones urbanas centrales. Todo ello merece una discusión que desborda los límites del presente trabajo, y que se abordará en futuras investigaciones. Igualmente importante, ubicada al Nordeste del arco, estaba la fuente del Juncal; elemento de topografía histórica conservado en Alcalá lo largo de los siglos, reformada varias veces a partir de sus estructuras romanas originales, la última a finales del siglo XIX para instalar un lavadero. Muy probablemente la fuente era un ninfeo ubicado junto a la entrada a la ciudad, y un lugar de culto y veneración quizá desde época prerromana (Rascón Marqués, 2004: 115 y ss.).

En segundo lugar, el río Camarmilla y el cinturón funerario. Se trata de una banda de terreno a modo de un arco que corre paralela al río Camarmilla, abrazando a la ciudad romana desde la puerta Oeste hasta la Norte. La prospección de 2012 no ha afectado a esta zona, pero la proliferación de diversos hallazgos a lo largo del siglo XIX, que se reflejan en diversas anotaciones y dibujos de los papeles Saldaña (Vallejo, 2005: 49 y ss., 143 y ss.), pero sobre todo en el croquis general de los hallazgos de 1893, 1894 y 1897 (Fig. 3), 


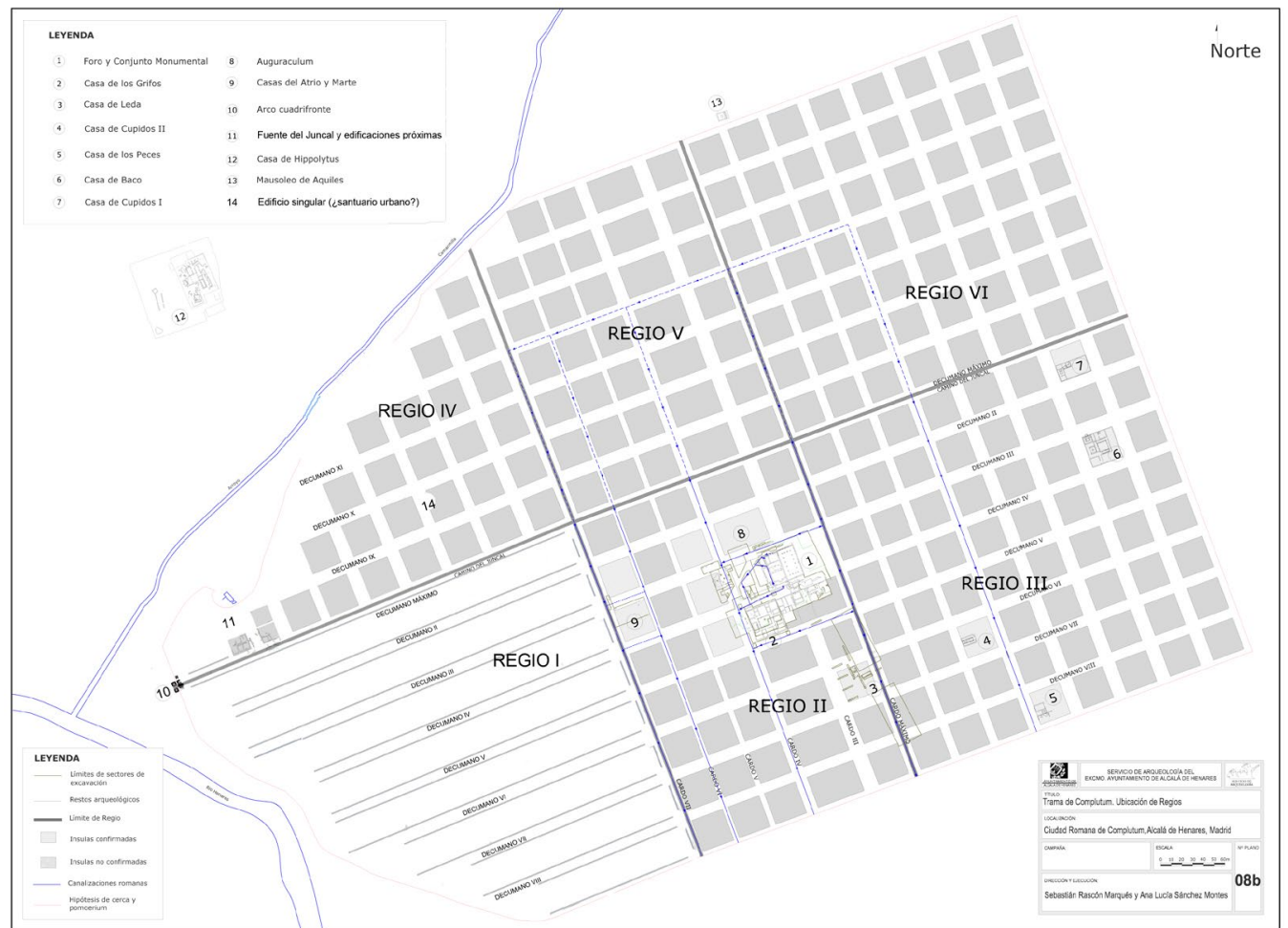

Figura 11: Hipótesis con la nueva trama urbana propuesta para la regio IV, actualizada con los datos proporcionados por la geofísica.

demuestran que existe una banda de terreno que podría leerse como una especie de «paisaje sagrado»: la propia fuente del Juncal, una serie de «cipos», varias inhumaciones, varias inscripciones funerarias, incluso edificios interpretables como mausoleos funerarios de cierta envergadura arquitectónica: el de Gayo Anio y Magia Atta (a todas luces un mausoleo, pues sus excavadores en 1881 encontraron inhumaciones dentro de sarcófagos de piedra y varios ajuares funerarios) y el llamado «panteón de Tito Valerio», donde además de la proximidad de restos funerarios indiscutibles existe un edificio cuya función, sin embargo, no tiene por qué ser necesariamente de esa naturaleza.

En tercer lugar, la trama urbana. La lectura de las anomalías refleja una trama predominante equiparable a la que se conoce para la mayor parte de la ciudad, y que se correspondería con la fundación de nueva planta de mediados del siglo I d.C., en general bien fechada en varios puntos de Complutum (Fig. 2). Sin embargo, tanto la geofísica como los restos arqueológicos inmediatos a la fuente del Juncal, demuestran que bajo esa trama urbana predominante subyacen otras alineaciones de muros que parecen reflejar una urbanización más antigua, que coincide con la orientación de la propia fuente del Juncal (Fig. 12), y que podría responder a un primer diseño urbano relacionado con el ninfeo y fechado hacia el cambio de Era en época de Augusto, en consonancia con las hipótesis vigentes en la actualidad sobre la historia de Complutum (Rascón Marqués y Sánchez Montes, 2014a: 311 y ss.).

En cuarto lugar, sin duda el probable santuario urbano constituye una importante aportación a la topografía urbana de Complutum. En una primera interpretación de las lecturas, se trataría de un recinto (el témenos) de unos $45 \mathrm{~m}$ de largo por unos $30 \mathrm{~m}$ de ancho, albergando en su interior una estructura rectangular, casi cuadrada, de entre 10 y $15 \mathrm{~m}$ de longitud, y orientado en dirección Norte-Sur. Como ya hemos dicho, esta interpretación se ciñe a las trazas más evidentes, que parecen referirse a una estructura con una delimitación periférica, marcando quizá el témenos (o un plinto); y en su interior un edificio que parece que podría corresponderse a una cela. Sin embargo, resulta posible otra interpretación: el recinto, en el eje Norte - Sur, mediría entre 65 y $70 \mathrm{~m}$, equiparable a dos módulos de $30 \mathrm{~m}$ mas aproximadamente la anchura de un decumano (Figs. 9 y 10). A este recinto se accedería por el Sur, desde el decumano IX, y por el Norte limitaría con el decumano XI. La anchura del recinto en cambio no se define con claridad, porque siendo claro el cierre por el Oeste, ninguna lectura permite aventurar un cierre por el Este. Pero en cualquier caso resultaría un recinto sagrado de gran superficie, albergando en su interior un edificio principal, plinto más cela, que se abriría al Sur, y con una serie de edificaciones complementarias a su espalda (al Norte) y a su izquierda(al Oeste); esta última, con las debidas reservas, recuerda a elementos que aparecen anexos a los templos, como son estanques, a modo de los dos que flanquean el templo de Diana en Mérida (Álvarez y Nogales, 2003: 173 y ss.) u otros elementos relacionados con el agua en el marco de la arquitectura religiosa, así el pozo de importantes dimensiones en el santuario urbano de Contributa Iulia (Mateos y 


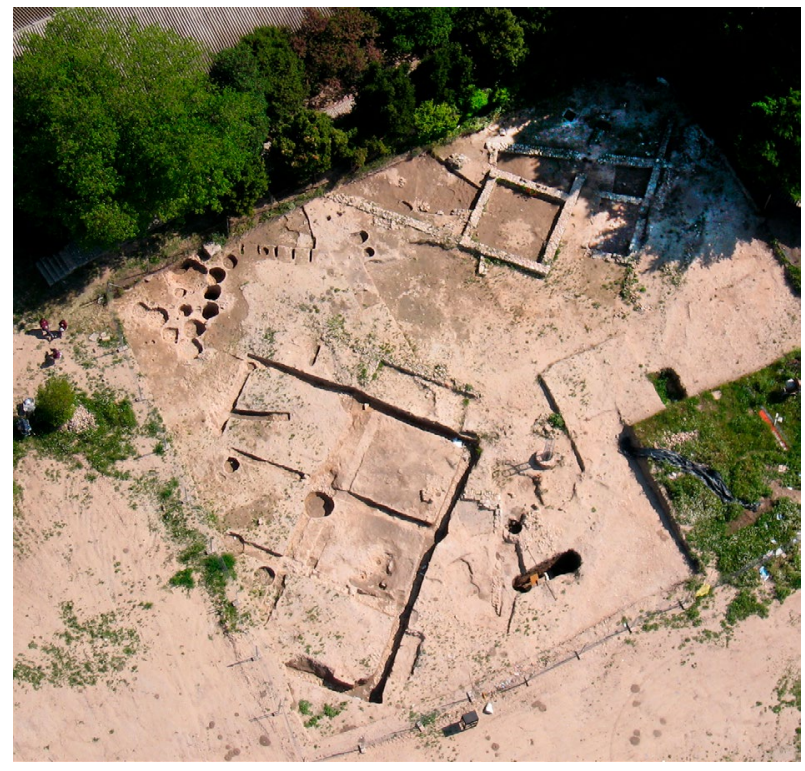

Figura 12: Fotografía aérea evidenciando, sobre los restos excavados, las dos alineaciones del diseño urbano detectadas en la regio IV.

Pizzo, 2015: 235; 242); por citar tan sólo dos ejemplos hispanos.

En cualquiera de ambos casos, la hipótesis más plausible es que nos encontremos ante un santuario urbano de importantes dimensiones, ya que se ajusta, según la hipótesis que elijamos, a una superficie de $45 \times 30 \mathrm{~m}$ (c. $1,5 \times 1$ actus) o a una longitud de 65 ó $70 \mathrm{~m}$ (c. 1 actus). En los dos casos, se trataría por sus dimensiones y su probable función, de una edificación pública de las más relevantes de las descubiertas hasta

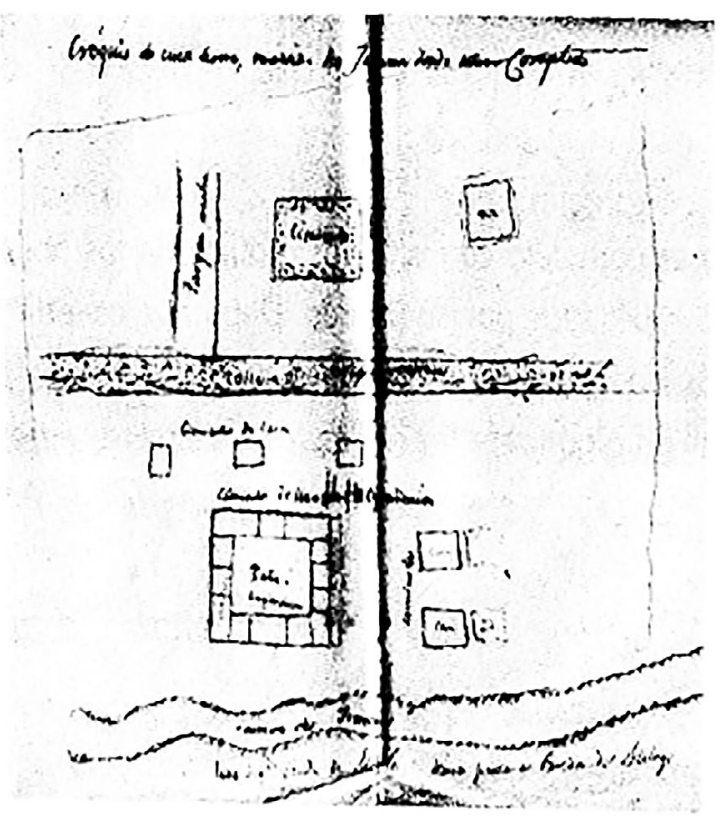

Figura 13: Croquis de José Demetrio Calleja con el hallazgo, entre otros restos, de una casa de peristilo en 1893, 1894 o 1897 (Vallejo, 2005: 156). la fecha en Complutum, comparable con las termas, basílica y cuadripórtico del área forense (a su vez, sobre una superficie de $2 \times 1$ actus). El hecho de tratarse de un santuario urbano es también especialmente interesante, ya que no siendo infrecuentes los templos en las ciudades hispanas, estos se encuentran por lo general vinculados a los centros monumentales de las mismas, relacionados con los foros; siendo su ubicación en espacios urbanos no centrales, a veces incluso próximos a las entradas, mucho más infrecuente en nuestro país. Mateos y Pizzo (2015) lo han puesto de relieve recientemente en referencia al santuario urbano hallado en Contributa Iulia, por cierto el paralelo más claro que hemos podido encontrar en España al probable templo complutense. Evidentemente, futuras investigaciones encaminadas a un estudio puntual de este interesante edificio deberán aportar mayor precisión sobre las hipótesis aquí propuestas.

Por fin, la lectura de las anomalías nos ayuda poco a definir la tipología y sobre todo la situación precisa de la mayoría de los edificios que ocupan la regio IV. Sin embargo, los datos del siglo XIX y de las excavaciones en torno a la fuente del Juncal permiten avanzar algunas conclusiones al respecto. En primer lugar, puede confirmarse la existencia de casas de carácter aristocrático. Existen en las excavaciones del XIX plantas identificables claramente como domus de peristilo: así, el croquis de los archivos Saldaña que muestra una casa de este tipo aparentemente muy próxima al camino del Juncal, es decir, el decumano Máximo (Fig. 13). Pero también en el croquis general de 1893, 1894 y 1897 (Fig. 4), el edificio en la parte superior izquierda de la imagen; y también, en el mismo croquis, el conjunto de estancias, algo más confusas, que ocupan la parte izquierda de la imagen, con lo que parece un patio definido parcialmente por plintos de columnas y una sala de cierta relevancia pavimentada con mosaico. En esta misma línea incidirían los mosaicos parcialmente documentados en el siglo XIX en esta zona (Vallejo, 2005: 157 y 158), dado que se trata de un material muy ligado (y muy especialmente en Complutum), a la edilicia privada de calidad. Hay que resaltar que en el marco de la investigación sobre la casa privada urbana complutense, el de peristilo es uno de los tipos de domus claramente identificados en Complutum, vinculándose a las casas de más importancia, como la de Baco o la de los Grifos (Sánchez Montes, 2014: 174 y ss.).

Pero además existen otros edificios caracterizados por la compartimentación interior en estancias de pequeñas dimensiones que se agrupan en líneas paralelas. Así, en el croquis de 1893, 1894 y 1897 (Fig. 4), el edificio situado al Este, en la parte central del dibujo, y denominado «casa grande». Y también el que aparece individualizado en los archivos Saldaña (¿o es el mismo, pero se trata de un croquis de detalle?) con la referencia de «cimientos de casa romana» (respectivamente, Vallejo, 2005: 156 y 157 -ver Fig. 14-). Se trata de uno o dos edificios de planta rectangular, de orientación 


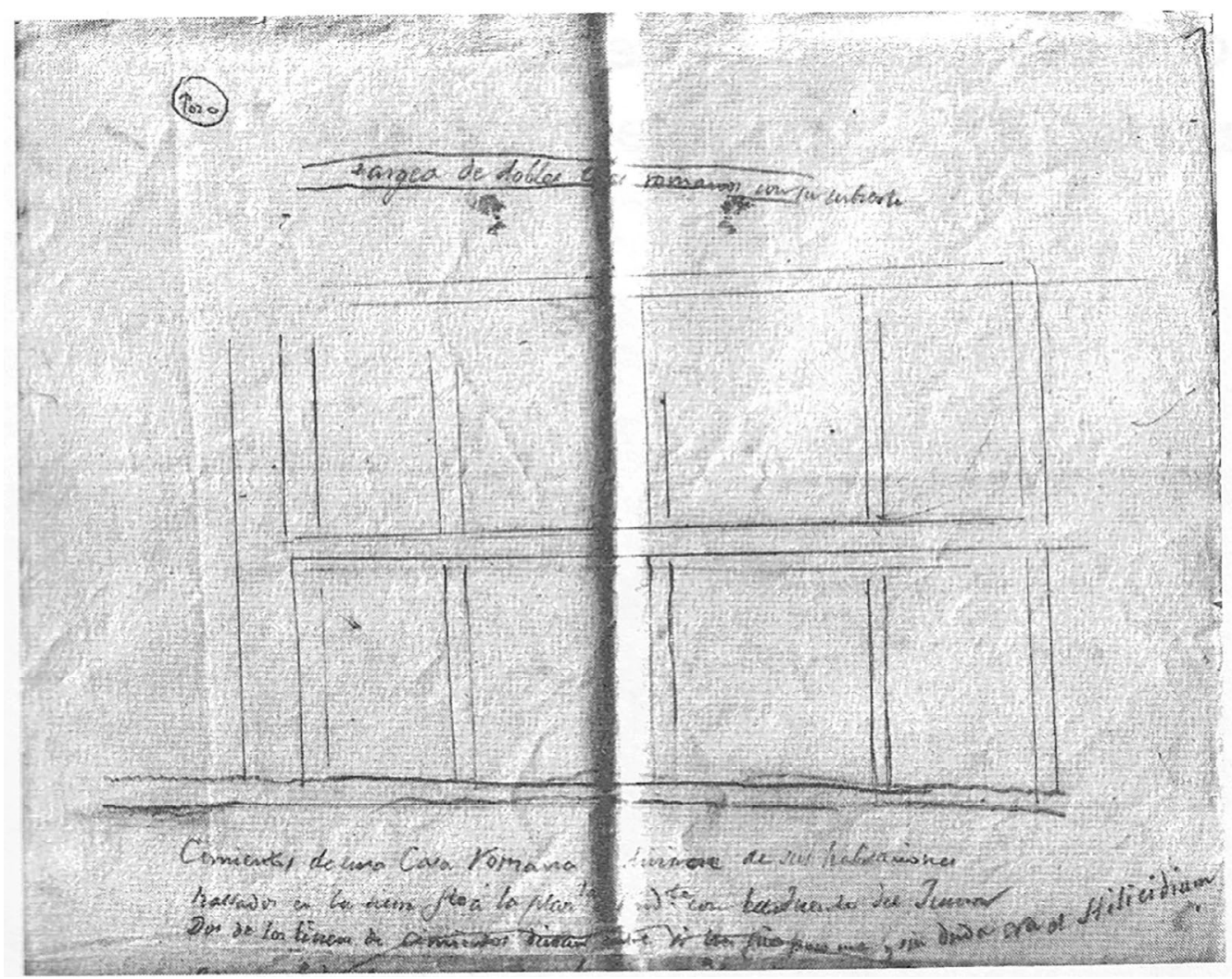

Figura 14: Croquis de José Demetrio Calleja con el hallazgo que él mismo denomina «cimientos de casa romana», en 1893 , 1894 o 1897 (Vallejo, 2005: 157).

Este - Oeste, estructurados longitudinalmente en dos mitades, y cada una de ellas compartimentada en un cierto número de recintos; muy probablemente, cada uno de estos edificios tiene dos fachadas con acceso directo desde la calle a cada uno de los recintos menores. Quizá estas estructuras se pueden vincular con las anomalías positivas de nuestro plano (Fig. 9), concretamente las estructuras longitudinales en la parte inferior izquierda, eso sí, muy alteradas por el probable expolio y abandono que sufrirían a partir de finales del XIX. Las estructuras excavadas en fechas recientes en el entorno de la fuente del Juncal, ciñéndose esta vez a una planta cuadrada, que no rectangular, evidencian una traza arquitectónica semejante y el mismo tipo de subdivisión interna (Fig. 12).

Algunas de estas estructuras están situadas además cerca de una de las entradas a la ciudad, y próximas a un edificio muy significativo de la misma (la fuente del Juncal). Otras, a partir de los croquis del siglo XIX, parecen relativamente cercanas también a este punto. $\mathrm{Su}$ interpretación es merecedora de estudios específicos, y por ahora nos limitaremos a apuntar que pueda tratarse de viviendas «para pobres» (de tipo apartamento o infraviviendas), de un tipo de posta para viajeros de paso, de almacenes relacionados con la entrada y salida de mercancías.... todo ello categorías conocidas, en mayor o menor medida, en otras ciudades romanas, pero también muy poco estudiadas por la arqueología de las mismas en nuestro país.

\section{CONCLUSIONES}

La prospección eléctrica de la regio IV de Complutum ha proporcionado un conjunto de datos muy interesantes sobre el urbanismo de la ciudad en este sector, y ha permitido avanzar en la interpretación de algunos de los edificios singulares excavados en el siglo XIX o a principios del XXI, cercanos a edificios emblemáticos de la ciudad, como el ninfeo de la fuente del Juncal.

Ha sido posible generar una nueva propuesta de urbanismo de insula cuadrada para la regio IV, acorde con la de la fundación de mediados del siglo I conocida para el resto de la ciudad. Así es más sencillo interpretar todas las anomalías lineales, e incluso entender las planimetrías del siglo XIX, y sus edificios más destacados. La resistividad ha proporcionado fuertes anomalías informes producto de la conjunción de escombreras modernas con estructuras antiguas, que son de difícil interpretación.

Por otro lado, cabe destacar la identificación de algunos edificios de planta cuadrada, que se refieren a la existencia de casas de peristilo; así como otras estructuras con compartimentaciones regulares en su interior, y cuya función no es fácil aventurar. Especialmente interesante es también el edificio singular al Este de la zona prospectada, de diseño rectangular, con una estructura cuadrada en su interior, y que con todas las precauciones debidas podría tratarse de un santuario urbano de importantes dimensiones. 


\section{REFERENCIAS}

Abascal Palazón, J.M. (2012). Ambrosio de Morales. Las antigüedades de las ciudades de España. Edición crítica del manuscrito. Madrid: Real Academia de la Historia.

Azcárraga Cámara, S. y Ruiz Taboada, A. (2013). Los orígenes de Complutum: el descubrimiento de la planta de la ciudad romana de San Juan del Viso (Villalbilla, Madrid). Anales de Arqueología Cordobesa, 23-24, 95-116.

Brito-Schimmel, P., Schimmel, M. y Carreras, C. (e.p.). Direcctional weighted mean/median filtering with application to magnetic archaeological survey data.

Calleja, J.D. (1898). Compluto romana. Estudio acerca de su importancia y de los notables objetos de arte hallados en sus ruinas. Revista de Archivos, Bibliotecas y Museos, 2, 1898, 171-187.

Carreras, C. (2013). Earth resistance survey: a mature archaeological geophysics method for archaeology. En C. Corsi; B. Slapšak; F. Vermeulen (Eds.). Good practice in archaeological diagnostics. Non-invasive survey of complex archaeological sites (pp.153-164). Springer.

Clark, A.J. (1986). Seeing beneath the soil: prospecting methods in archaeology. Londres. Routledge.

Gaffney, C., Gater, J. y Ovendon, S. (1991). The Use of Geophysical Survey Techniques in Archaeological Evaluations. Institute of Field Archaeologists Technical Paper, 9. Reading: University of Reading.

Gaffney, C. y Gater, J. (1993). Development of Remote Sensing Part 2: Practice and method in the application of geophysical techniques in archaeology. En J. Hunter y I. Ralston (Eds.). Archaeological Resource Management in the UK (pp. 205-214). Stroud: Alan Sutton.

Gaffney, C. y Gater, J. (2003). Revealing the buried past. Stroud: Tempus.

Hesse, A. (2000). Count Robert du Mesnil du Buisson (1895-1986), a French precursor in geophysical survey for archaeology. Archaeological Prospection, 7, 43-49.

Imai, T., Sakayama, T. y Kanemori, T. (1987). Use of roundprobing radar and resistivity surveys for archaeological excavations. Geophysics, 52 (2), 137-150.

Keay, S., Earl, G., Hay, S., Ogden, J. y Strutt, K. (2009). The Role of Integrated Geophysical Survey Methods in the Assessment of Archaeological Landscapes: the Case of Portus. Archaeological Prospection, 16, 154-166. DOI: https://doi. org/10.1002/arp.358

Kermorvant, A. y González, C. (2000-2001). Complutum, Alcalá de Henares. Detections Geophysiques. Note Fin de Misión. Inédito. Informe presentado al Servicio Municipal de Arqueología de Alcalá de Henares. DOI: https://doi. org/10.1002/arp.358

Lowrie, W. (1997). Fundamentals of geophysics. Cambridge: Cambridge University Press.

Mateos Cruz, P. y Pizzo, A. (2015). Un santuario urbano hallado en Contributa Iulia (Medina de las Torres,
Badajoz). Lucentum, XXXIV, 231-246. DOI: http://dx.doi. org/10.14198/LVCENTVM2015.34.09

Rascón Marqués, S. (2004). Complutum Hispanorromano. La ciudad y su territorio. Inédito. Tesis Doctoral. Universidad Autónoma de Madrid.

Rascón Marqués, S. y Sánchez Montes, A. L. (2010). Complutum, el Campo Laudable, Qala't Abd al-Salam y el Burgo de Santiuste. Centros urbanos y suburbios de Alcalá de Henares en la Antigüedad y la Edad Media. En D. Vaquerizo Gil (Ed.). Las áreas suburbanas en la ciudad histórica. Topografía, usos, función. Monografías de Arqueología Cordobesa, 18 (pp. 335-362). Córdoba: Universidad de Córdoba y Gerencia de Urbanismo de Córdoba. Recuperado de: http:// www.academia.edu/3649362/Complutum_el_Campo_Laudable_Qala_t_Abd_al_Salam_y_el_Burgo_de_Santiuste. Centros urbanos y suburbios de $\overline{\mathrm{A}} \mathrm{lcal} \% \overline{\mathrm{C}} 3 \% \mathrm{~A} 1 \mathrm{de} \mathrm{He}-$ nares_en_la_Antig\% $\%$ C3\%BCedad_y_la_Edad_Media

Rascón Marqués, S. y Sánchez Montes, A. L. (2013). Cloacas de Complutum (Alcalá de Henares, Madrid). En F. de A. Escudero Escudero y M.P. Galve Izquierdo. Las cloacas de Caesaraugusta y elementos de urbanismo y topografía de la ciudad antigua (pp. 370-386). Zaragoza: Institución Fernando el Católico.

Rascón Marqués, S. y Sánchez Montes, A. L. (2014a). Complutum: de la ciudad clásica a la deconstruida a través de 700 años de historia. En D. Vaquerizo Gil, J.A. Garriguet y A. León (Eds.). Ciudad y territorio: transformaciones materiales e ideológicas entre la época clásica y el Altomedioevo. Monografias de Arqueología Cordobesa, 20 (pp. 309-324). Córdoba: Universidad de Córdoba. Recuperado de: http:// www.academia.edu/19647130/Complutum_de_la_ciudad cl\%C3\%A1sica_a_la_deconstruida_a_trav $\%$ C3\%A9s de_700_a $\% \mathrm{C} 3 \% \overline{\mathrm{B}} 1 \mathrm{os}$ _e de_historia

Rascón Marqués, S. y Sánchez Montes, A. L. (2014b). Urbanismo de la ciudad romana de Complutum (Alcalá de Henares, España). En J.M. Álvarez Martínez, T. Nogales Basarrate e I. Rodà de Llanza (Eds.). Actas del XVIII CIAC: Centro y periferia en el mundo clásico (pp. 1683-1687). Mérida: Museo Nacional de Arte Romano. Recuperado de: https://www.academia.edu/19575736/Urbanismo de la ciudad_romana_de_Complutum_Alcal\%C3\%A1_de_Henares_Espa $\% \mathrm{C} 3 \% \overline{\mathrm{B}} \overline{\mathrm{l}} \mathrm{a}$ _? auto $=$ download

Rascón Marqués, S. y Sánchez Montes, A. L. (2015). Urbanismo de la ciudad romana de Complutum. En J.L. Valle Martín (Coord.). Evolución histórica del urbanismo complutense (pp. 33-70). Alcalá de Henares: Institución de Estudios Complutenses.

Rascón Marqués, S. y Sánchez Montes, A. L. (2017). La ciudad romana de Complutum: nuevos datos, nuevas interpretaciones. Actas del Congreso Vides Monumenta Vetera. Zona Arqueológica, 20(1), 127-143.

Sánchez Montes, A. L. (2014). La casa privada urbana en la ciudad de Complutum (Alcalá de Henares, España). En J.M. Álvarez Martínez, T. Nogales Basarrate e I. Rodà de Llanza (Eds.). Actas del XVIII CIAC: Centro y periferia en el mundo clásico (pp. 1097-1101). Mérida: Museo Nacional de Arte Romano. 
Scollar, I., Tabbagh, A., Hesse, A. y Herzog, I. (1990). Archaeological Prospecting and Remote Sensing. Cambridge: Cambridge University Press.

Simms, J.E. y Albertson, P.E. (2000). Multidisciplined investigation to locate the Kentucky shipwreck. Geoarchaeology an International Journal, 15(5), 441-468. DOI: https:// doi.org/10.1002/(SICI)1520-6548(200006)15:5<441::AID$\mathrm{GEA} 3>3.0 . \mathrm{CO} ; 2-8$
Strutt, K. y Fry, R. (2007). Report on the Geophysical Survey in the ager tarraconensis, Catalonia, October 2007 (SREP 17/2007). Informe inédito.

Vallejo, M. (2005). El solar de Complutum. Memoria histórica de la arqueología en Alcalá de Henares. Cuadernos de Patrimonio Histórico y Arqueológico, 1. Alcalá de Henares: Ayuntamiento de Alcalá de Henares.

Weymouth, J.W. (1986). Archaeological site surveying programa at the University of Nebraska. Geophysics, 51(3), 538-552. DOI: https://doi.org/10.1190/1.1442108 